\title{
The Role of Egyptian Non-Governmental Organizations in Integrating the Differently Abled ${ }^{1}$
}

\author{
Laila El Baradei
}

Professor of Public Administration, School of Global Affairs and Public Policy, The American University in Cairo

\begin{abstract}
From a rights perspective, disabled citizens should have access to education, health, employment, and information services similar to all other citizens. Besides governments, civil society organizations have an important role to play. The aim of the current research paper is to explore the role of Egyptian non-governmental organizations in integrating the "differently abled" citizens in society. After reviewing the range of theoretical models used in studying disability, whether the individualistic/medical model, the social model, or the biopsychosocial model, a case study approach is used to study the work of four non-governmental organizations (NGOs) working with the disabled in Egypt. Findings revealed that the implicit disability model adopted by the different NGOs influenced their activities, their perception of challenges faced, and their recommendations for improved effectiveness. While the traditional NGOs followed the individualistic/medical model of disability, the other, relatively newer NGOs leaned more towards the social model.
\end{abstract}

\section{Keywords}

Differently Abled, Disabled, Non-Governmental Organizations (NGOs), Integration

\section{Introduction}

Disability is a rising field of inquiry. The term "disability" has various definitions. The World Health Organization defines disability as "an umbrella term for impairments, activity limitations and participation restriction. [It] is the interaction between individuals with a health condition and personal and factors" (WHO, 2013). Similarly, the OECD defines the disabled person as one "who is limited in the kind or amount of activities that he or she can do because of on-going difficulties due to long term physical condition, mental condition or health problem. Short disabilities due to temporary conditions such as broken leg and illness are excluded. Only disabilities lasting for more than six months [are] included" (OECD, 2001). Additionally, the UN Convention on the Rights of Persons with Disabilities defines persons with disabilities as "those who have long term physical, mental, intellectual or sensory impairments which in interaction with various barriers may hinder their full and effective participation in society on an equal basis with others" (United Nations, 2006, p. 1). Similarly, the Disability Discrimination Act of the UK defines a disabled person as one who has: "a physical or mental impairment which has a substantial and longterm adverse effect on their ability to carry out normal day to day activities" (DDA, 1995, S1(1) as quoted in Williams et al., 2008, p. 12). Thus, the focus in all these definitions is on long term physical or mental impediments to the full participation of citizens in society. The idea is that "No disability, however slight, nor however severe, implies lesser moral, political or ethical status, worth or value" (Harris, 2001, p. 383). The disability definitions describe all the dimensions of disability that provide a full understanding of the meaning of a disabled citizen. The definitions also provide an overview of how international organizations describe the disabled person.

Interestingly, other organizations and scholars no longer use the term "disabled" in referring to groups of citizens who are physically or mentally impaired, but realize that sometimes those individuals have other more superior abilities and prefer using the term "Citizens with Special Abilities" or citizens who are "Differently Abled"

\footnotetext{
${ }^{1}$ Acknowledgements are due to Ms. Sherihan Hashem, the American University in Cairo, for her valuable research assistance.
} 
(Ahmed \& Ansari, 2013). The term Differently Abled will be the one preferred for this research although both terms disabled and differently abled may be used interchangeably in specific contexts.

In Egypt, although the right of all citizens to be treated equally and fairly is clearly spelled in the constitution and most other official documents, differently abled citizens are usually left out of the equation. Article 9 of Egypt's 2014 constitution states that: "The state ensures equal opportunity for all citizens without discrimination" (ConstituteProject, 2019). In preparing the budget, the law's preamble states that "The Egyptian citizen should feel that he is the focal point of the government concern and care" (Egyptian Ministry of Finance, 2012, p. 11). However, Egypt is a country that has a restrictive environment for differently abled people. Egypt's economic and social environment unfortunately establishes limitations that hinder the full participation of differently abled people in society. The barriers have many forms and cover a range of different sectors and spheres ranging from unfriendly transportation services to, most importantly, the exclusion in many laws and regulations of a mention of the disabled, and then the weak enforcement of the laws that do provide benefits to the disabled (Hagrass, 2005, p. 149).

Meanwhile, there is no agreement over the exact number of differently abled people in Egypt. In 2004, an estimate of the number of differently abled citizens showed that there were about 2.6 million (low estimate) to 6.9 million (high estimate), and that $25 \%$ of the population were affected indirectly by disability, if we include those representing the family of the differently abled person and the caregivers involved. Some other studies refer to $7 \%$ to $10 \%$ of the population being disabled (United Nations, 2011, p. 5). Other studies refer to a ten million figure for the number of disabled citizens, including 2 million disabled children (Al-Bawabah News, 2014). The Egyptian Central Agency for Public Mobilization and Statistics (CAPMAS) has categorized disability as follows: blind, deaf, lost limb(s), or mentally retarded; adding to these in 1996 dwarfs, paralysed people, and other disabilities (Hagrass, 2005, p. 155). However, all these figures are semi-outdated. Research also points to the fact that families do not usually like to report the presence of a disabled member in the family, for fear sometimes of social stigmatization, a matter that further shows the wide scope of the problem and the probability of the data reported being low estimations, rather than the opposite (United Nations, 2011, p. 5). Moreover, there is no national development plan for disabled citizens, nor developmental policies. The laws and regulations for disability are poorly enforced. According to Law No. 39 for 1975, there is a five percent employment quota for citizens with disabilities, but many societal barriers hinder the differently abled person from being able to compete in the market (Hagrass, 2005, p. 158).

Governments have an important role to play in integrating differently abled citizens into society and providing for their different set of needs, yet there is no doubt that civil society also has a similarly significant role to play. Since the mid-1980s, according to the New Public Management model of management in the public sphere, and according to the new widely adopted good governance ideologies worldwide, governments should not do everything themselves, but rather should partner with civil society and the private sector in achieving their objectives and getting things done. This applies to the issue of the disabled as with all other issues of public concern. Adopting the creed that all citizens should be given an equal opportunity to participate and enjoy a good quality of life in society, regardless of age, sex, colour, or ability, this paper aims to explore the role of Egyptian non-governmental organizations in integrating differently abled citizens in society. The main research question posed is: how can Egyptian non-governmental organizations play an effective role in integrating and embracing the differently abled in society to the benefit of all parties concerned? The research aim is to shed more light on the efforts of the NGOs in Egypt concerned with disabled citizens and their role in integrating them into the society. Some of the investigative research questions suggested include:

- What are the different types of services offered by these organizations?

- What are some of the challenges they encounter in trying to pursue their mandate?

- What are some suggested policies and actions needed to enhance the effectiveness of these NGOs? 


\section{Methodology}

To answer those questions, the methodology used in the study included a literature review checking into the recent findings regarding dealing with differently abled citizens and the different models and approaches utilized in the study of the differently abled. Moreover, the research utilized the case study approach to present four in-depth reviews and analyses of different types of NGOs in Egypt dealing with the differently abled. The case study approach was chosen as it provides on-the-ground analysis of the disabled status in Egypt; other statistical figures would not provide a solid enough basis. To develop each case study, data were collected about the organizations from the published literature, available reports, web data, and newspaper articles, plus actual visits to the organizations, observation of the work conducted, and implementation of a number of in-depth targeted interviews with officials working in these NGOs.

\section{Literature review}

\section{Increased concern with disability issues}

Ever since the 1980s there has been increasing interest in the concern for disability. Starting with the UN declaring 1981 as the International Year of Disabled Persons, to the UN adopting a World Programme of Action Concerning Disabled Persons in 1982, followed by the African Decade of Disabled Persons 2000-2009, the European Year of People with Disabilities in 2013, the Asian and Pacific Decade of Disabled Persons 2003-2012, and finally, the Arab Decade of Disabled Persons 2002-2006 (Albert, 2006, as quoted in Barnes, 2012). In parallel, over the past 30 years more and more scholars and advocates adopted the doctrines of the social model and the socio-political models versus the individual or medical model. The social model and the socio-political models have been used as major advocacy tools by activists calling for the rights of the disabled. Disability is now regarded not just as a medical condition but more as a human rights issue (Barnes, 2012).

\section{Why the need to integrate differently abled citizens?}

Before we proceed further with our study it is important to present the different rationales clarifying why we need to integrate differently abled citizens into society. Individuals with disabilities are citizens with equal rights as everybody else (Msafiri, 2014). From a human rights perspective and in conformance with many constitutions calling for equal rights for all, they should have at least the same access to education, health, employment, and information services as all other citizens. In many cases, a person is disabled more through societal imposed restrictions on accessibility, rather than by any physical infliction he or she has. A simple thing such as the lack of ramps may render a person disabled in the eyes of society. People "with disabilities are able, just differently able" (Copeland, 2011, p. 237). In 2000 more than 180 countries endorsed the Millennium Development Goals including the target of universal education for all children. If we are going to leave out of the equation all the disabled children, then we will not be able to achieve what we have set out to do (Filmer, 2008, p. 141). The Sustainable Development Goals raise similar questions. When disabled citizens face problems in accessing needed services, it not only affects them negatively, but also their families are affected (Zidan, 2012). Furthermore, from an economic and state financial perspective, it may be less of a burden on the state in the long run, if the disabled citizens can be integrated into the labour force. It may be more cost efficient and effective to provide support and incentives to those differently abled who can work, rather than just providing easily accessible benefits to those who cannot work because of disability (OECD, 2010).

In Egypt, there is no agreement over the exact number of disabled citizens. In 2004, an estimate of the number of disabled citizens showed that there were about 2.6 million (low estimate) to 6.9 million (high estimate), and that $25 \%$ of the population were affected indirectly by the disability; if we include those representing the family of the disabled person and the caregivers involved. Some other studies refer to seven percent to $10 \%$ of the population being disabled (United Nations, 2011, p.5). Other studies refer to a ten million figure for the number of disabled 
citizens, including 2 million disabled children (Al-Bawabah News, 2014). CAPMAS has categorized disability as follows: blind, deaf, lost limb(s), or mentally retarded. adding to them in 1996 dwarfs, paralyzed people, and other disabilities (Hagrass, 2005, p. 155). However, all these figures are semi-outdated. Research also points to the fact that families do not usually like to report the presence of a disabled member in the family, for fear sometimes of social stigmatization; a matter which further points out to the wide scope of the problem and the probability of the data reported being low estimations, rather than the opposite (United Nations, 2011, p. 5). Moreover, the laws and regulations for disability are poorly enforced. According to Law No. 39 of 1975, there is a five percent employment quota for citizens with disabilities, but many societal barriers hinder the differently abled person from being able to compete in the market (Hagrass, 2005, p. 158).

\section{Increased global concern with disability issues}

Ever since the 1980s there has been increasing global interest and concern with disability. Starting with the UN declaring 1981 as the International Year of Disabled Persons, to the UN adopting a World Programme of Action Concerning Disabled Persons in 1982, followed by the African Decade of Disabled Persons 2000-2009, the European Year of People with Disabilities in 2013, the Asian and Pacific Decade of Disabled Persons 2003-2012, and finally, the Arab Decade of Disabled Persons 2002-2006 (Albert, 2006, as quoted in Barnes, 2012). In parallel, over the past thirty years more and more scholars and advocates have adopted the doctrines of the social model and the sociopolitical models versus the individual or medical model. The social model and the sociopolitical models have been used as major advocacy tools by activists calling for the rights of the disabled. Disability is now regarded not just as a medical condition but more as a human rights issue (Barnes, 2012).

\section{Conceptual discussions and models of disability}

Different conceptual models and framings for disability abound in the literature. These models guide how policy makers and practitioners go about their work in dealing with the differently abled. They also influence how the public perceive disability (Smart, 2009).

One framing of disability employment policy distinguishes between two main approaches: the individualistic approach versus the social approach. While the individualistic approach considers the disabled person as the centre of the problem and tries to secure his/her employment by giving incentives to employers, the social approach considers the society to be the reason for the problem and tries to introduce changes to the environment in which disabled people function, in order to secure their integration, and to ensure compliance with citizenship values where all are equal (Lunt \& Thornton, 1994). The social framing of disability considers that the differently abled person and the qualities he/she is born with do not turn into disabilities except when the society starts perceiving them as such, and places him/her in a dependent situation (Copeland, 2014). According to the social model, the group of social and political factors affecting the physically impaired person are those which turn him into a disabled individual. Disability is the result of society's inability to provide needed services to the physically impaired (Lang, 2007).

Other studies discuss three different models of disability: the medical model, the social model and the biopsychosocial model. The medical model is explained in similar terms to the individualistic approach above where the focus of disability is on the individual and on his/her medical condition, and not on how society is organized. The social model emphasizes that having an impairment is not the cause of disability, but that individuals with similar impairments may be disabled in different ways depending on how the surrounding society reacts to them. Finally. the bio-psychosocial model integrates both the medical and the social models and perceives disability as impacted by both medical and social factors (Williams et al., 2006). Other studies also discuss this link between both the medical and social models under the title "Weflarist Approach," where the interaction between biology, psychology, and the surrounding environment is perceived to be the reason behind disability (Savulescu, 2011). 
In yet another attempted typology of disability models, a distinction is made between the bio-medical model, versus the functional model and the socio-political model. The interpretation of the bio-medical model is very much similar to the medical and the individual models where the disability is thought of as a dysfunction within an individual, and the treatment is focused on medical rehabilitation of the individual. The second model in this typology or categorization is the functional model where, again similar to the social model, the emphasis in treatment is on providing accommodation for the disabled and adapting the surrounding environment to enable him/her to be more functional, especially at work. As for the third model in this typology, the socio-political model, also referred to as the "Minority Group Model," neither the individual, nor the environment, are seen as the causes of the problem and as the areas where treatment should be directed, but rather the problem is linked to the lack of civil rights for the disabled and the fact they don't receive equal opportunities as other members in society (Smart, 2009). Therefore, the solution to disability according to the last model is to try to change laws and to try to change people's attitudes.

Among the proposed strategies for developing a society where disabled citizens live a full life and enjoy equal rights are enacting anti-discrimination laws whereby discriminating against the disabled would be illegal, securing access to information so that disabled people can understand more how policies are made and on what basis, and working on developing infrastructures that meet the needs of the disabled in the various sectors, whether education, health, transportation, or otherwise (Lang, 2007).

\section{NGOs working with differently abled citizens in Egypt}

Over the past years the number of non-governmental organizations working with the disabled has increased. One study states that their number has increased from 232 in 1996 to around 336 in 2001 (Egypt General Information Agency, 2014). Non-governmental organizations working with differently abled citizens in Egypt can be categorized in more than one way. By venue of registration, we can have a group of international versus local NGOs. However, we can also categorize by the type of service provided and the activities performed. There are some NGOs that provide foster homes for differently abled citizens and/or recreational activities to enhance their talents; others focus on advocating for their cause and fight for changing laws and policies; and there are organizations which are interested in building the capacity of the disabled and providing them with better ways to engage in society through employment and education. NGOs can also be categorized based on their point of intervention in the development stage in the life of the differently abled citizen that they are targeting with their efforts. There are five stages that NGOs can work on: diagnosis, early integration, schooling, higher education, and training and development. The annex to this paper includes a list of various examples of both international and local Egypt-based NGOs working with differently abled citizens.

\section{The four case studies}

In presenting the four case studies of different NGOs in Egypt working with the differently abled, basic comparison variables were identified and used to show as to each case the differences and similarities. Variables include reasons for selection, background information, years of establishment, vision and mission, target group of beneficiaries, main activities and achievements, main challenges, and recommendations for improved performance. Face-to-face interviews were conducted with ANWA, ASWB, and Helm officials, and a phone interview with a Damg representative at SETI was conducted as well. Interviews included questions like mission type, targeted segments of disabled in Egypt, funding, and challenges. All interviews were taped.

The reason for choosing those four specific NGOs is as follows:

- ANWA is the most popular traditional NGO in Egypt, with a significant number of beneficiaries of different ages. They specialize in one kind of disability (visual disabilities). Choosing ANWA as case study will give a full view of how the NGOs for disability in Egypt operate, providing an insight into what could possibly be the challenges for the small NGOs that target different types of disabilities or that have different visions from 
ANWA. Also, choosing ANWA provided a full picture of how the Egyptian government supports the most known disability NGO.

- ASWB is considered to be the second very well-known NGO located in a busy place such as Helipolis. The reasons for choosing it are similar to the reasons for choosing ANWA, but here the case is different regarding the targeted disability type and number of beneficiaries.

- Helm was a source of hope for the disabled in Egypt, and it was chosen to be studied in this research because it has a whole new vision and brand-new challenges as an Egyptian NGO targeting disabled people. It is also a brand-new NGO founded by two young people. It is a magnet for research and the reasons for its foundation were prominent.

- Damg combined both the old and new schools of NGOs targeting the disabled in Egypt. Both young and traditional staff are working at SETI premises. It is considered as well to have a unique approach.

\section{Selection methodology}

The above four Egypt based non-governmental organizations were selected as case studies for this research. An attempt was made to choose four different NGOs in terms of years of establishment, focus of work, target beneficiaries, and work methods. After a quick review of the work of many NGOs that work with the differently abled in Egypt, the decision was made to focus on the four NGOs of Al Nour Wal Amal ANWA, meaning in Arabic Light and Hope; Al Som Wal Bokm ASWB, meaning the Deaf and Dumb; Helm, meaning Dream; and Damg, meaning Integration. Two of the NGOs are very traditional in terms of years of establishment and also in terms of focus on one main type of disability (ANWA and ASWB), while the other two have been newly established and provide their services to all differently abled citizens whatever the disability may be (Helm and Damg).

The four NGOs are considered the top NGOs working on disability in Egypt. They are chosen to give a full view of disability status and hopes for the present and future in Egypt. Moreover, each NGO's role in integrating disabled people into Egyptian society is fully analyzed to answer the main research question.

One on one interviews are considered one of the most data reliable research approaches; that's why it was chosen to conduct the four case studies. It gave the interviewees time to think and elaborate on their answers.

\section{Background Information}

ANWA was established in 1954 so it is one of the oldest established NGOs working with the differently abled.

ASWB is also a traditional type of NGO established in 1954. The founder himself became deaf when he was given the wrong medicine as a child (Hawaa Magazine, 2012).

Helm is a relatively newly established NGO. Helm NGO was founded in 2011 by two American University in Cairo alumni, Amena El-Saie and Ramez Maher. Later in 2013 an AUC students' Helm club was also established with the aim of extending to other university campuses later on. Helm is still awaiting the license from the Ministry of Social Affairs.

Damg is also a relatively new initiative established under the umbrella of a more traditional NGO, Caritas Egypt, which is affiliated with Caritas International. Caritas Egypt was established in 1967 and registered with the Ministry of Social Affairs. SETI Center, a division of Caritas, established much later in 1986, focuses on the problem of the disabled in Egypt. SETI stands for support, education, and training for inclusion and hence the short Arabic name Damg which means integration or inclusion.

\section{Vision \& mission statements}

The mission statement for ANWA NGO is to cater to the needs of Egyptian blind women and girls through providing them with free education, literacy programs, vocational training and job opportunities (Ahram Online, 2021). There is an emphasis on nourishing talents, especially musical talents, besides providing vocational training. ANWA goals include integrating blind girls into society through training them to excel in professions that 
are commensurate with their disabilities, eradicating their illiteracy, nurturing and developing their musical talents, and finally working on their overall education including helping them acquire computer skills. "We fight for human rights. We fight for the rights of women and girls who are blind," says the President of ANWA (AlMajalla, 2013).

The ASWB mission is to support deaf and dumb disabled citizens, whether adults by helping them find suitable jobs, or children by helping them through providing education rehabilitation services.

For Helm its vision is to provide adequate care and aid to the millions of Egyptians suffering from disabilities and to assist them with training and development that can help them get the job that suits each person's particular competencies. Its mission is to facilitate the employability process and increase job opportunities by connecting people with special needs with employers and helping to launch and support for-profit-businesses with inclusive employment policies. "We want to stop businesses from hiring people with disabilities because they feel pity for them. Instead, what we want to do, is show people that those with disabilities can be an asset to society and the economy, not a burden" (Helm, n.d.). "We believe that having a disability does not mean the person is disabled. If we are able to turn Egypt into an 'enabling environment,' then people with disabilities can be involved in all aspects of life. [People with disabilities] are very strong willed and determined but the society they live in suppresses any and all of their dreams. As a result they also give up and do not strive to achieve their goals. They allow society to pin them down," said El Saie, one of Helm organization founders (Daily News Egypt, 2013).

For Damg the mission is to improve the quality of life for the largest possible number of persons with disabilities and their families especially those with urgent needs. The belief is by adopting a family and community approach, which targets family and community members with the rehabilitation efforts, instead of just focusing on the differently abled person, this leads to more effective results.

\section{Beneficiaries}

ANWA NGO works with only blind and visually impaired girls and women.

ASWB beneficiaries are citizens with hearing and speaking disabilities.

Helm targets all differently abled people looking for job opportunities.

Damg targets all differently abled citizens in need of help and their families but gives special attention to school children.

\section{Main activities and programs}

ANWA has two main sections in its organizational structure. One focuses on music training and the other on vocational training, which is referred to as the 'productive sector'. The music section is the more famous. It is considered one of the very few and unique all-blind orchestras that play western classical music in addition to oriental music. Starting with a group of 15 blind girls, they now have a full orchestra made up of 44 musicians, 2040 years of age, playing all the various instruments including string, percussion, brass, and woodwind, and a junior orchestra made up of 27 girls from 8-20 years of age. A number of conductors have taken the lead in training the orchestra and over the years have managed to master techniques enabling the girls to play without reading musical notes and without following the traditional baton of the maestro. The girls learn everything by heart but at some stage they also get to learn the musical notes following the braille system. The girls are trained separately and as a group. In 1988, the orchestra first travelled to perform in Austria. The praise and applause received won them invitations from many other parts of the world and since then the ANWA orchestra has travelled to over 25 different countries. Their performances have been met with great appreciation and with standing ovations from the different international audiences who got to hear them (Ms. Ebtesam, personal communication, May 28, 2014); Ahram Online, 2013). In March 2014, the ANWA girls' orchestra celebrated its $60^{\text {th }}$ year anniversary at the Cairo Opera House (Ahram Online, 2014).

The vocational section of ANWA covers different types of training activities for girls involving straw and bamboo weaving, knitting, carpet making, socks manufacturing, plastic products, and sewing. Different 
workshops are affiliated with ANWA, each specialized in one of these products. Training continues over a period of two years after which ANWA issues a Certificate of Rehabilitation for each girl from the Egyptian Centre of Rehabilitation at the government Labour Force Office. After that, certified graduated girls become eligible for work in any public or private company and can possibly be hired to fill the five percent quota for the Disabled according to the Labour Law. The Labour Office works on contacting companies and organizations to fill their five percent quota by including the certified graduates of ANWA.

Regular courses are provided to the trainees on Effective Citizenship and Orientation and Movement. The aim is to help them build self-esteem and navigate the streets on their own. Additionally, there is a celebration for the day of the Blind People on the $14^{\text {th }}$ of November of each year, similar to the Orphans' Day. Parents are also called in and offered a course on how to deal with their daughters and how to build their self-confidence. All girls are given obligatory literacy classes, since the majority are illiterate, and once they are ready, they sit for the Ministry of Education literacy exam and are given a certificate equivalent to fifth year in primary school. Occasionally the girls are given computer training. There is an ANWA school up to the secondary level, and girls are encouraged to continue their studies, but the aim more is to help them professionally rather than educationally. Exceptionally, some girls complete their university education and there are some success stories, like that of Dr. Saida who is a university professor in Suez city (Mona, Social Specialist, personal communication, April 15, 2014)).

ASWB trains children on sign language and provides vocational training programs with the purpose of helping the deaf and dumb integrate in society and find jobs. They help children with developing special computer skills and using computer-aided reading programs to be able to join regular schools (ASWB Speech and Hearing Specialist, personal communication, April 15, 2014). Among the main achievements of ASWB is developing a special Arabic dictionary for sign language that combines both the picture of the sign and the corresponding alphabet letter (Hawaa Magazine, 2012).

The Helm NGO campaigns and advocates for disabled rights. One of their successful campaigns took place during the writing of the Egyptian constitution in 2014 and was entitled "Zayee Zayek" (We are the same). It was a nationwide campaign advocating for the rights of disabled Egyptians in education, employment, and healthcare. "The main goal was to recognize the existence of disabled people and declare their full rights to live and dream of a better life in which they are welcomed and their abilities are utilized," said the president of Helm American University in Cairo students club, which participated in the campaign (AUC News, 2014). Helm has started building a database collecting CVs of disabled persons seeking employment from other NGOs serving people with disabilities and from employer announcements of job vacancies. They then provide their match making services to both clients. Helm's other activities include provision of vocational training to groups of disabled citizens in arts and crafts, such as jewelry making. They cooperate with other NGOs, such as Tatweer E-learning Initiative, to market the manufactured products online (Al-Ahram Weekly,2014).

Damg provides training to personnel dealing with citizens with disabilities, organizes awareness campaigns at the community level, offers vocational rehabilitation services for disabled citizens at their home premises, provides resources, and educational and training materials to people working with the disabled, and in a more focused manner helps with the education process for children with special needs in schools and kindergartens (Seti Center, 2014). For school integration programs, Damg provides courses to parents under the title of Family Support to help educate them about the best methods for supporting one another, cooperating to solve students' problems, and other problems encountered (Damg Official, personal communication, April 24, 2014). Among Damg projects was a pilot inclusive education project implemented from 1999-2001 in three governorates in Egypt, Cairo, Alexandria, and Al-Menya, in cooperation with the Ministry of Education and through support from Save the Children and UNESCO in order to test the results of including children with special needs in regular classes in the primary and kindergarten levels. Later, from 2003-2008, another phase of the inclusive education project was implemented again through external funding and piloting inclusive methods in 15 primary schools and 15 kindergartens. Positive outputs included building the capacity of 500 teachers and 360 students with special needs, empowering 300 parents, and decreasing behavior problems in the schools (Seti Center, 2014). 


\section{Sources of funding}

For ANWA NGO the main sources of funding are donations received for charity purposes and through fund raising efforts targeting business associations. The orchestra is a major source of revenue generation for the NGO. ANWA also realizes some revenues out of the sale of the products produced by the trainees, which are sold in occasional exhibitions held at schools and clubs, or at the annual fair held by the NGO itself.

ASWB does not receive any government assistance. It depends mainly on fund raising.

For Helm the main resources relied upon are the volunteers and their own time and personal resources, plus the technical assistance they receive from the other more well-established NGOs in the field such as Caritas Egypt and the Maadi Advanced School and Center, which advise Helm when the need arises.

Damg had international funding up until 2008, but when the funding ended, it started fund raising from both Egyptian and international funding agencies.

\section{Main challenges}

According to the ANWA NGO, amongst the main challenges faced are the psychological problems of the blind trainees who may either be living in the NGO dorms or living with their parents and commuting every day to attend the training sessions. Dealing with the blind girls is challenging because it requires special skills and training for the employees who will work with them. For example: "Girls have to be touched when saying hello, not just greeted by voice [...]. The fact that they are living together makes them feel normal, unlike if they are living at their homes they don't feel normal among their families" said Ms. Mona, social specialist at ANWA (Personal communication April 15, 2014).

Training blind and visually impaired girls on functioning in day-to-day life activities is also a challenge. Training is provided on how to use the white sticks, but the girls prefer not to do so because it makes them feel weak. Moreover, getting around in the streets of Egypt is very challenging. There is a need for more speaking ads and speaking devices to show directions, but these do not exist (Mona, Social Specialist, personal communication, April 15, 2014).

Lack of publicity and awareness of the activities of the ANWA NGO is a challenge. As mentioned, there is a day for celebrating the blind and the white sticks, but it does not receive any attention in the Egyptian media.

After the Revolution of January 25, 2011 in Egypt and over the following period, ANWA's orchestra faced serious funding issues. Egyptian people are reported not to be as keen as before on attending concerts because of the situation of political and economic turmoil the country is passing through. This affected the ability of the orchestra to purchase instruments and led to a cut down in travel (Al-Monitor, 2014).

For ASWB, the main challenges the officials emphasized did not have to do with the disabled beneficiaries themselves, but rather with the parents of the deaf or dumb children who were not aware of how to deal with their children. The other main obstacles mentioned had to do with the efforts of the organization to secure employment opportunities for their beneficiaries and the problems encountered with both the Labour office and the potentially employing companies (Mona, Social Specialist, personal communication, April 15, 2014). Additionally, it always proves difficult to integrate the disabled with so-called normal people. Among the embarrassing situations cited affecting Egyptian deaf citizens is that the law requires that when they go to the notary office, they have to make use of a judicial appointee, similar to the procedure used with the mentally disabled and prisoners, as explained by the founder of ASWB (Hawaa Magazine, 2012).

According to the Secretary General of ASWB, after the 25 January Revolution in 2011, there were very high expectations that the needs of the disabled in general and the deaf and dumb in particular, would be heeded more, however this did not happen. "What we aspired to in terms of social justice, did not materialize. We still feel today that Mubarak's regime is still present. [For the disabled] nothing was implemented in housing, employment, health, education or any other sector", said Mostafa Ibrahim, ASWB Secretary General (El Balad, 2012). 
For Helm NGO, the main challenges mentioned by the interviewed official were related to the lack of available accurate information including census data regarding the number of disabled Egyptians in the four main categories of disability, whether physical, visual, hearing, or mental, and additionally the lack of acceptance of the Egyptian society of the differently abled and the hurdles imposed on their integration. The lack of real enforcement of the five percent employment quota for the differently abled was also a major concern. "The disabled person tends to take a sick leave forever and receive a monthly stipend. Only few are willing to work and engage in the society”, said Ms. El Saie, Helm founder (El Saie, A., personal communication, March 22, 2014). Doubts were also cast on the role of the government in monitoring the quota enforcement. While it should be monitoring the enforcement, this is not taken seriously. Companies also sometimes manipulate the data about the number of employed differently abled individuals and the Labour office may choose to ignore the situation in some large companies.

For Damg, the main challenges mentioned had to do with the curricula used for teaching children who are differently abled and the lack of needed school facilities. The government of Egypt recently decided that disabled children should be integrated in the regular schooling system. However teachers are not clear about how to deal with the disabled children. They use the same curricula used for the other children with no adaptations, there are no teachers' assistants to accompany the disabled child, or to repeat the lesson, and no suitable teaching aids are available for the differently abled. Additionally, the schools are not provided with ramps or adequate preparations for the disabled (Damg Official, personal communication, April 24, 2014). The decision to integrate the school children with special needs with their peers in public schools was issued by the Minister of Education in 2009 and covered the integration of nearly 30 thousand students (Egypt General Information Agency, 2014). Despite the plans to train teachers in areas of physical therapy, speech therapy, and psychological counselling, the abovementioned problems persist.

\section{Suggestions}

Many suggestions were provided by the different interviewed officials and managers in the studied NGOs.

ANWA officials called for increased awareness and publicity for the blind as happens with other societal groups. Orphans Day is much celebrated in the media, but very few people hear about the day for the blind.

The Helm NGO founder pointed out the importance of instilling in the differently abled a positive attitude that would enable them to overcome any sensitivities they have towards their disabilities. They need to be constantly motivated and provided with psychological help when needed. Other regular employees in the companies that employ the differently abled need to be given orientation sessions to help them avoid stereotyping. The top-level management needs to be subjected to more awareness sessions to understand the needs of the differently abled and the importance of giving them an employment opportunity.

The Helm NGO founder also suggested that the government needs to provide incentives to companies to hire the differently abled, such as providing them with tax reductions or exclusive market shares or help them with campaigning for the employment of differently abled citizens.

The Helm founder also discussed the need for companies to facilitate transportation to and from the workplace for its disabled employees.

The Helm former AUC Club president (Abdel Moneim, M., personal communication, April 14, 2014) pointed out the need for companies to adjust their work processes and work flows to accommodate the differently abled. They also need to update their computer software systems and provide training in organizational behaviour to the employees in the whole company to learn how to deal effectively with their differently abled colleagues.

The ASWB president and founder mentioned a number of suggestions for improving the overall situation of the deaf and dumb in Egypt. He proposed replacing the required judicial appointee accompanying the deaf and dumb at notary offices, with an expert in sign language. According to the director and founder of ASWB, there needs to be a Coordination Office for Disabled Children that determines the percentage of disability, sets quotas for their enrolment in various regular schools, provides medical and financial support to buy the needed medical 
tools, like hearing aids, teaches them sign language. and gives them speech therapy sessions to enable them to interact smoothly with other healthy citizens (Hawaa Magazine, 2012).

The Damg official recommended that the only way to improve the integration of differently abled students in the regular schooling system is through increasing the awareness of all the different stakeholders that deal with the students, that is, the teachers, parents, and educational workers. Also adjusting the curriculum according to the differently abled needs will increase their willingness to learn and be pioneers in the future.

\section{Main findings}

To sum up, many interesting findings were derived from the study:

- In Egypt, there is no agreement on the exact number of 'differently abled' citizens and no accurate statistics exist;

- Reasons behind the need for integrating the 'differently abled' into society include a combination of human and civil rights issues, economic and financial efficiency issues, plus a need to fulfil the MDGs targets;

- Ever since the 1980s there has been an increased concern with the issues of disability and repeated international and regional assurances of this concern through naming years and decades to be devoted to the rights of the disabled;

- NGOs in Egypt working with the disabled can be categorized in different ways: either by geographical location, years of service, scope of disability types covered, or stage of intervention in the life of the disabled;

- The four NGOs selected for case studies in this qualitative research represented most different designs where two were very traditional and two relatively newly established, two were working with one type of disability and two with all types of disabilities;

- The implicit disability model adopted by the different NGOs influenced the articulation of their vision and mission statements, their activities, their perception of challenges faced and their recommendations for improved effectiveness;

- The starkest finding is that the traditional NGOs - ANWA and ASWB - follow more the individual and medical model of disability, while the other relatively newer NGOs Damg and Helm - lean more towards the social model of disability.

- While the focus in the requests of ANWA and ASWB were on providing better direct support to their beneficiaries, in the other two organizations, Damg and Helm, the focus was not only on the individuals they are serving, but also on society as a whole. Repeatedly in the articulation of vision and mission statements, and in the selection of activities, ANWA and ASWB mentioned the needs of blind women and deaf and dumb citizens, focusing on them as individuals needing training, development, and supporting tools and equipment. On the other hand, in the cases of Helm and Damg their vision statements mentioned 'a family and community approach', awareness sessions for the community, working with employers, and advocating for changes in the Egyptian constitution. Helm worked with the employers to secure jobs and worked on raising awareness of the public to accept the differently abled as productive members in society. Similarly, Damg in its attempts to integrate the differently abled children in regular schools focused on training teachers, and on the need to change curricula and amend policies.

- ANWA and ASWB in stating the different challenges they face in their work again focused mostly on the individual psychological problems, and individual skills needed by their constituents. However, the other two newer NGOs Helm and Damg in citing the main challenges they face referred more to different stakeholder groups besides their direct beneficiaries, such as the employers and the government, the lack of accurate data, the poor enforcement of the law stipulating an employment quota for the disabled, the need for ramps and adequate preparations in the surrounding environment.

- Similarly, the proposed recommended solutions by the different NGOs used as case studies reflected the same dichotomy between the individual versus the social and psycho-sociopolitical models to a great extent. Even when the traditional NGOs, ANWA and ASWB, pointed to requested changes in the social and political 
environment in which they were operating, their calls were for other actors, mainly the government, to work on improving the situation. However, in the case of the two newer NGOs, Damg and Helm, when they identified proposed solutions outside their direct sphere of interest, they adopted a more proactive role and pointed out what they were doing in changing the social and political environment through organizing awareness campaigns, through contacting potential employers to modify their work processes and work flows, and through increasing the awareness of teachers and parents and educational workers to enable better integration of the 'differently abled' in the regular schooling systems.

\section{Conclusions}

Although the four case studies by no means offer a comprehensive picture of the situation of the disabled in Egypt, yet many useful insights can be derived from the review and analysis. I think the more we move towards the social model and even towards the psychosocial model in dealing with disability as NGOs in Egypt, the more we will be moving in the right direction. The question is no longer about dealing with a medical case, or a physical impairment for an individual. The new research in the field and the newer models of disability - the social model and the psycho/socio-political model - call for considering the overall environmental context for the problem, for social acceptance of the differently abled in society, for raising public awareness, for adapting infrastructure, for educating the abled citizens, and for advocating for changes in laws and policies so that there are equal citizenship rights for all. The social model has proven its success in many countries, as it encourages the whole society to accept the differently abled in many different ways. The more our traditional NGOs catering for the needs of the differently abled get to understand these more comprehensive perspectives needed for their work, the better and the more effective impact they will have on the integration of their constituencies in society.

\section{References}

Ahram Online. (2013, October 28). "Fikry: Inspiration for Al-Nour Wal Amal blind musicians' orchestra". https://english.ahram.org.eg/News/84956.aspx

Ahram Online (2014, March 2). Al Nour Wal Amal Chamber Orchestra to celebrate 60th anniversary in Cairo Opera House. http://english.ahram.org.eg/NewsContent/5/33/95036/Arts--Culture/Music/AlNour-Wal-Amal-ChamberOrchestra-to-celebrate-th-.aspx [Accessed 30 August 2021]

Ahram Online. (2021, January 24). "Egypt's Al-Nour Wal Amal blind women orchestra opens Brazil's music festival”. https://english.ahram.org.eg/NewsContent/5/33/399471/Arts--Culture/Music/Egypts-AlNour-Wal-Amal-blindwomen-orchestra-opens.aspx

Al Ahram Weekly. (2014, April 22). https://english.ahram.org.eg/Portal/50/Al-Ahram\%20Weekly.aspx

Al-Bawabh News Website (2014). https://www.albawabhnews.com [Accessed 30 August 2021].

Al-Majalla (2013). Playing in the Dark: Al Nour Wal Amal orchestra: When hopes and dreams are realized. http://www.majalla.com/eng

AUC News (April 2014). http://www.aucegypt.edu/newsatauc

Bakr, T.E. (2013, April 8). Helm wins first prize. Daily News Egypt. http://www.dailynewsegypt.com/2013/04/08/helm-wins-first-prize/ [Accessed 30 August 2021]

Barnes, C. (2012). The Social model of disability: Valuable or irrelevant?, in N. Watson, A. Roulstone \& C. Thomas, (Eds.), The Routledge Handbook of Disability Studies (12-29). Routledge.

ConstituteProject (2019). Egypt's Constitution of 2014 as amended through 2019. https://www.constituteproject.org/constitution/Egypt_2019.pdf?lang=en2014

Copeland, C.A. (2011). Library and information center accessibility: The differently abled patron's perspective. Technical Services Quarterly, 28(2), 223-241. https://doi.org/10.1080/07317131.2011.546281

Egypt General Information Agency. (2014). Ministry of Education. http://www.sis.gov.eg 
Egyptian Ministry of Finance. (2012). Circular Preparing State’s General Budget FY2013/2014.

El-Balad (2013, January 26). Deaf and Dumb Caring Society. http://www.el-balad.com

El-Rashidi, S. (2014, May 15). Egypt's blind women's orchestra struggles post-revolution. Al-Monitor. http://www.almonitor.com/pulse/originals/2014/05/egypt-blind-women-orchestra-nour-amal.html\#\#xzz32xXPPuy

Filmer, D. (2008). Disability, poverty and schooling in developing countries: Results from 14 household surveys. The World Bank Economic Review, 22(1), 141-163. https://doi.org/10.1093/wber/lhm021

Handicap International (2006). Taking a step forward, views from stakeholders on disability policies and services in Egypt, Jordan and Lebanon. Working paper no.1.

Hagrass, H. (2005). Definitions of disability and disability policy in Egypt. In C. Barnes \& S. G. Mercer (Eds.). The social model of disability: Europe and the majority world (pp. 148-162). The Disability Press.

Harris, J. (2001). One principle and three fallacies of disability studies. Journal of Medical Ethics, 27, 383-387. https://dx.doi.org/10.1136\%2Fime.28.3.203

Hawaa Magazine (2012, April 5). Director of the deaf and dumb NGO: I demand a Higher Council for the disabled. http://hawaamagazine.com/posts/402970

Helm (n.d.) Home [Facebook page]. Facebook. http://www.facebook.com/Helmegypt

Lang, R. (2007). The Development and critique of the social model of disability. Leonard Cheshire Disability and Inclusive Development Center. http://www.ucl.ac.uk/cl-ccr/centrepublications/workingpapers [Accessed 30 August 2021]

Lunt, N. \& Thornton, P. (1994). Disability and employment: Towards an understanding of discourse and policy. Disability and Society, 9(2) 223-238. https://doi.org/10.1080/09687599466780231

Msafiri. (2014). Empowering the disabled. Information Development, 30(1), 95.

Patel, M. A. I., and Ansari, M. A. (2013). Education of differently abled children: Governmental interventions and attainments. Indian Streams Research Journal, 3(11), 1-5.

Savulescu, J., \& Kahane, G. (2011). Disability: a welfarist approach. Clinical Ethics, 6(1), 45-51. https://doi.org/10.1258\%2Fce.2011.011010

Seti Center website (2014). http://www.inclusive-education.seti-center.com/home_e.htm [Accessed 30 August 2021]

OECD (2001). Glossary of statistical terms. https://stats.oecd.org/glossary/detail.asp?ID=2046

OECD (2010). Breaking the barriers: A Synthesis of findings across OECD countries. OECD Series Sickness, disability and work. https://read.oecd-ilibrary.org/social-issues-migration-health/sickness-disability-and-workbreaking-the-barriers_9789264088856-en [Accessed 30 August 2021]

Smart, J. F. (2009). The power of models of disability. Journal of Rehabilitation, 75(2), 3-11.

United Nations Convention on the Rights of Persons with Disabilities Article 1. https://www.un.org/development/desa/disabilities/convention-on-the-rights-of-persons-with-disabilities.html

Williams, B., Copestake, P., \& Eversley, J. (2008). Experiences and expectations of disabled people: A research report for the Office of Disability Issues. Office for Disability Issues, Department for Work and Pensions. https://webarchive.nationalarchives.gov.uk/ukgwa/20110218173408/http://odi.dwp.gov.uk/docs/res/eedp/eedpfull-report.pdf

World Health Organization (2015). Disability and health, fact sheet number 352. https://www.who.int/en/newsroom/fact-sheets/detail/disability-and-health [Accessed 30 August 2021].

Zidan, T. (2012). Orienting social workers to the disability movement in Egypt: Implications for practice. Journal of Human Behavior in the Social Environment, 22, 755-769. https://doi.org/10.1080/10911359.2012.692584 